\title{
Failure of added dietary gluten to induce small intestinal histopathological changes in patients with watery diarrhea and lymphocytic colitis
}

\author{
HUGH JAMES FREEMAN MD
}

HJ FrEEMAN. Failure of added dietary gluten to induce small intestinal histopathological changes in patients with watery diarrhea and lymphocytic colitis. Can J Gastroenterol 1996; 10(7):436-439. Lymphocytic colitis is a form of microscopic colitis usually characterized by watery diarrhea and often associated with biopsy-defined celiac disease. Two patients with lymphocytic colitis and normal small intestinal biopsies who were administered $40 \mathrm{~g}$ of added dietary gluten for four consecutive weeks are presented. Small intestinal biopsies from multiple sites in the proximal small bowel were done after three and four weeks to determine whether pathological changes in latent celiac disease could be induced in these patients with a high gluten-containing diet. In addition, colorectal biopsies were done to determine whether the colitis was sensitive to oral gluten. No alterations in the small intestinal biopsies were detected in either patient and no changes occurred in colitis severity. Although microscopic forms of colitis have been linked to celiac disease, this study indicates that lymphocytic colitis is a heterogeneous clinicopathological disorder that, in some patients, is independent of any gluten-induced intestinal pathological changes.

Key Words: Celiac disease, Collagenous colitis, Gluten, Latent celiac disease, Lymphocytic colitis, Microscopic colitis
L'ajout de gluten alimentaire échoue à induire des changements histopathologiques intestinaux chez les patients qui présentent de la diarrhée et une colite lymphocytaire

RÉSUMÉ : La colite lymphocytaire est une forme de colite microscopique habituellement caractérisée par de la diarrhée aqueuse et souvent associée à une maladie cœliaque définie par la biopsie. Le cas de patients souffrant de colite lymphocytaire et présentant des biopsies du grêle normales, qui avaient reçu $40 \mathrm{~g}$ de gluten alimentaire supplémentaire pendant quatre semaines consécutives, est présenté ici. Les biopsies du grêle provenant de multiples sites du grêle proximal ont été effectuées après trois et quatre semaines afin de déterminer s'il était possible de modifier la maladie coliaque latente chez ces patients à l'aide d'un régime à forte teneur en gluten. De plus, des biopsies colorectales ont été effectuées afin de déterminer si la colite était sensible au gluten oral. Aucune altération des biopsies du grêle n'a été décelée chez les patients et lagravité de la colite n'aété aucunement modifiée. Bien que des formes microscopiques de colite aient été associées à la maladie coeliaque, cette étude indique que la colite lymphocytaire est une maladie clinico-pathologique hétérogène qui, chez certains patients, est indépendante des anomalies pathologiques intestinales induites par le gluten.
Tn 1980, the term 'microscopic colitis' was coined to denote a chronic mucosal inflammatory process in colorectal biopsies from patients with diarrhea and macroscopically normal or near-normal endoscopic examinations of the colon (1). Subsequent pathological studies (2-5) documented a predominance of intra-epithelial lymphocytes (ie, epithelial lymphocytosis); as a result, the term 'lymphocytic colitis' emerged. Although lymphocytic colitis is a very distinctive histopathological entity in patients with diarrhea, it shares some clinical and histological features with another form of microscopic colitis, collagenous colitis (4-8). The intra-

Department of Medicine (Gastroenterology), University of British Columbia, Vancouver, British Columbia

Correspondence and reprints: Dr Hugh Freeman, ACU F-137, Vancouver Hospital (UBC Site), 2211 Wesbrook Mall, Vancouver, British Columbia V6T 1W5. Telephone 604-822-7216, fax 604-822-7236

Received for publication October 3, 1995. Accepted December 5, 1995 
epithelial lymphocytes in lymphocytic colitis also appear to stain positively with T cell markers (eg, MT-1) (9).

Both lymphocytic and collagenous colitis have been recognized in patients with celiac disease (9-13). Indeed, in an initial report (9), lymphocytic colitis was recognized in 12 of 39 celiac disease patients (31\%). A later study recorded lymphocytic colitis in 13 of 30 elderly celiac disease patients (43\%) (14). Similar observations were reported in gastric epithelium from celiac disease patients (15) and, very recently, in biliary ductal epithelium from a patient with celiac disease and sclerosing cholangitis (16). Finally, pathological studies report that up to $40 \%$ of patients with collagenous colitis have celiac disease (17). This has led to the recommendation that exclusion of unrecognized or clinically occult celiac disease is essential if a microscopic form of colitis, such as collagenous colitis, is detected (17).

Celiac disease may be clinically occult and initially diagnosed only after a small intestinal biopsy. In some patients with dermatitis herpetiformis, for example, histological features of celiac disease may be found in the small intestine (18). In others, however, intestinal biopsies may be normal and small bowel changes typical of celiac disease may be induced with prolonged administration of added dietary gluten (19). This response to increased dietary gluten has been termed 'latent' celiac disease (19).

In the present study, a high gluten-containing diet was administered to patients with microscopic (lymphocytic type) colitis who had normal small intestinal biopsies without characteristic changes of celiac disease. Repeated small intestinal biopsies were done to determine whether the histopathological features of latent celiac disease could be elicited in the small intestine.

\section{PATIENTS AND METHODS}

Two patients with watery diarrhea had colorectal biopsies showing changes typical of lymphocytic colitis (Figures 1,2). These changes have been previously described in the author's earlier studies of patients with celiac disease (9) and include the following: lymphocytic infiltration of the superficial epithelium, with or without crypt lymphocytosis; chronic inflammation of the lamina propria; epithelial cell damage or reactive nuclear changes; and an absence of crypt abscess formation or crypt distortion. Biopsy specimens showing these changes were also routinely assessed for subepithelial collagen layer deposition typical of collagenous colitis. In both patients reported here, quantification of colonic superficial epithelial lymphocytes revealed counts over 30 lymphocytes per 100 epithelial cells (9) and intra-epithelial lymphocytes stained positive for MT-1 (9).

Other investigations for possible causes of diarrhea, including hemogram, serum chemistry tests (bilirubin, protein, albumin, iron and iron binding capacity, carotene, folic acid and vitamin $\mathrm{B}_{12}$ ), fecal examinations for ova and parasites, fecal bacterial cultures and fecal bacterial toxin assays, were normal or negative. A lactose tolerance test was negative. Barium radiographic studies of the upper and lower gastrointestinal tracts were normal. Small intestinal biopsies

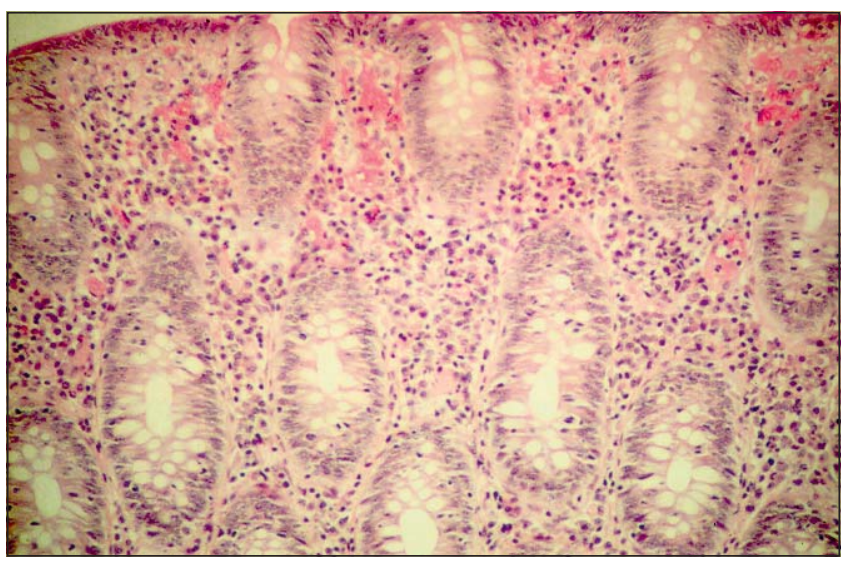

Figure 1) Rectal mucosal biopsy from a 48-year-old female with watery, nonbloody diarrhea for two years. Other investigations, including small intestinal biopsies, were normal. Colonoscopic examination was normal but microscopic changes of lymphocytic colitis were present

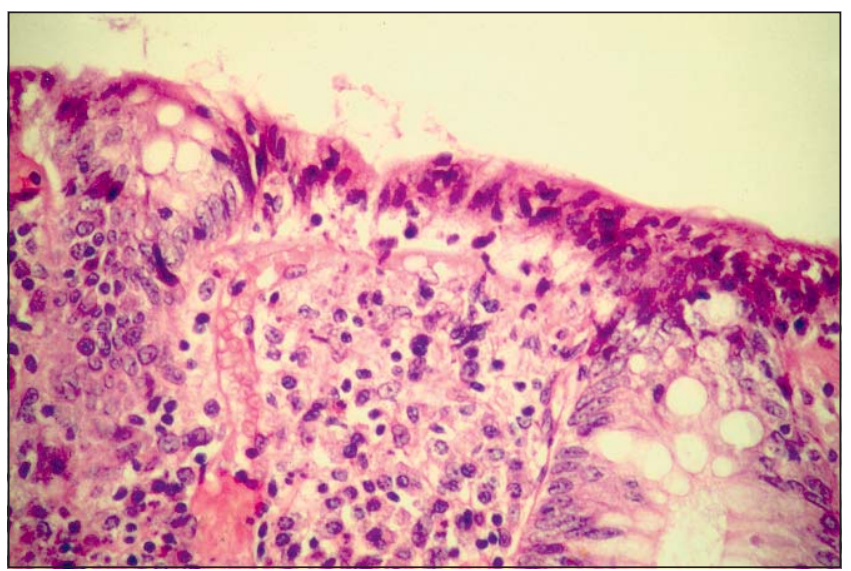

Figure 2) Rectal mucosal biopsy from a 46-year-old female with intermittent watery diarrhea for six years. Symptoms resolved with prednisone treatment but promptly recurred with cessation of the corticosteroid medication. Investigations while symptomatic with diarrhea, including small intestinal biopsies, were normal. Colonoscopic examination was normal but microscopic changes of lymphocytic colitis were present

from different sites were normal. In addition, endoscopic gastric biopsies were normal in both patients, with no features of lymphocytic gastritis (16) or collagenous gastritis (20).

\section{RESULTS}

Both patients provided informed consent for these studies. Based on a retrospective dietary recall evaluation, it was estimated that their daily consumption of gluten was approximately 5 to $7 \mathrm{~g}$ /day. Neither patient had a history of travel to a foreign country (21). After hospitalization in a clinical investigation unit, a high gluten diet consisting of $40 \mathrm{~g}$ of dietary gluten daily for four weeks was administered, similar to the quantity of gluten used in an earlier investigation of latent celiac disease (22). Patients were monitored daily by the investigator and a hospital dietitian for dietary compliance. After three and four weeks, respectively, for both patients, repeated biopsies were done from at least three 
separate sites in the proximal small intestine (descending duodenum, transverse portion of the duodenum, duodenojejunal junction). All biopsies were interpreted as normal; there were no histological features of celiac disease and no alterations in intraepithelial lymphocyte numbers.

Gluten-free diet administration in patients with lymphocytic colitis was previously shown to have no effect on diarrhea in most patients (23). Colorectal biopsies after added gluten in both patients in this study demonstrated persistent epithelial lymphocytosis with no change in intraepithelial lymphocyte number.

\section{DISCUSSION}

Lymphocytic colitis is a form of microscopic colitis, usually characterized by watery diarrhea. Diagnosis is established by histological evaluation of colorectal biopsies. Endoscopic and radiological evaluations are generally normal. Although the etiology of lymphocytic colitis is not clear, previous studies have noted that celiac disease frequently accompanies it, and the two conditions are often diagnosed concurrently (9). In most patients with lymphocytic colitis and celiac disease, epithelial lymphocytosis remains unchanged with a gluten-free diet (9). Because celiac disease may be present in some patients with microscopic colitis, Armes and colleagues (17) recommend that small bowel biopsies be done to exclude celiac disease, especially in symptomatic patients.

In the present study two patients with watery diarrhea and colorectal biopsies showing lymphocytic colitis had normal small intestinal biopsies. A high gluten diet was administered over a prolonged period in a controlled environment to determine whether latent celiac disease was present. In both patients, repeated biopsies of the small intestine were normal and the lymphocytic colitis persisted, which strongly suggest that lymphocytic colitis is a heterogeneous histopathological disorder that may be independent of any gluteninduced intestinal disease.

Although the clinical and pathological features of lymphocytic colitis are similar, the present studies imply, therefore, that this form of microscopic colitis may be either primary - with no obvious association to another clinical disorder - or secondary - with a close link to other disorders, such as celiac disease. Indeed, in a very recent report (21), lymphocytic (microscopic) colitis was associated with tropical sprue and, interestingly, a favourable clinical response to tetracycline treatment. Recent histopathological studies in patients with collagenous colitis have also implied a similar evolving form of classification, with some cases associated with or secondary to celiac disease (10-13).

Latent celiac disease has been defined as a condition in which the intestinal mucosa becomes unequivocally abnormal in response to increased dietary gluten (19). This subclinical form of celiac disease has been best documented in two small intestinal biopsy studies in disorders clinically linked to celiac disease. In one study (19), two nonhospitalized patients with dermatitis herpetiformis (and initially normal small intestinal biopsies) developed mucosal ab- normalities after ingesting a high gluten diet containing an additional 13 to $15 \mathrm{~g}$ of gluten/day; moderate and severe small bowel biopsy alterations were seen at 10 and 12 weeks, respectively. These findings were later confirmed in another centre (24).

In another study (22), a hospitalized patient with normal small intestinal biopsies and a history of lymphoma developed mucosal abnormalities within three weeks of continual consumption of an additional $40 \mathrm{~g}$ of gluten/day.

Small bowel biopsy changes were also described in patients challenged with $10 \mathrm{~g}$ of gluten/day for an average of 11.9 weeks to demonstrate the gluten-dependent nature of the skin rash in dermatitis herpetiformis (25). These findings confirmed earlier observations (26). In another report (27), asymptomatic relatives of patients with celiac disease showed small intestinal crypt lengthening after their normal diet was supplemented with $40 \mathrm{~g}$ of gluten/day for six weeks. Although excessive quantities of gluten may cause 'toxic' small bowel changes, biopsies obtained from normal volunteers in three studies $(19,25,27)$ have shown no changes. Finally, it has been established that consumption of up to $150 \mathrm{~g}$ of gluten/day for at least eight weeks had no demonstrable histological effect on the small bowel of normal volunteers (28).

It may be that these traditionally accepted and defining histological features of celiac disease will have to be eventually altered or extended to include other serological (eg, antigliadin, antireticulin or antiendomysial antibodies) or pathological markers in celiac disease such as high intraepithelial lymphocyte counts (29) and high gamma-delta expression of intraepithelial lymphocytes (30-32). It has recently been proposed that these be labelled 'potential celiac disease' patients (33). The precise relevance of these proposed investigations or criteria for the diagnosis of celiac disease and its relationship to other clinical disorders, such as lymphocytic colitis, however, are not known and require further evaluation.

\section{CONCLUSIONS}

Studies strongly suggest that this form of microscopic colitis with epithelial lymphocytosis (or lymphocytic colitis) is a heterogeneous clinicopathological entity. While this disorder has recently been linked to celiac disease and reported in a patient from India with tropical sprue, it may also be observed independently of any evident small intestinal disease or even gluten-induced small intestinal pathology. Important links to other conditions are likely but their recognition in patients with lymphocytic colitis is still required.

\section{REFERENCES}

1. Read NW, Krejs GJ, Read MG, Santa Ana CA, Morawski SG, Fordtran JS. Chronic diarrhea of unknown origin. Gastroenterology 1980;78:264-71.

2. Kingham JG, Levinson DA, Ball JA, Dawson AM. Microscopic colitis - a cause of chronic watery diarrhea. BMJ 1982;285:1601-4.

3. Bo-Linn GW, Vendrell DD, Lee E, Fordtran JS. An evaluation of the significance of microscopic colitis in patients with chronic diarrhea. J Clin Invest 1985;75:1559-69.

4. Lazenby AJ, Yardley JH, Giardiello FM, Jessurun J, Bayless TM. 
Lymphocytic (microscopic) colitis: a comparative histopathologic study with particular reference to collagenous colitis. Hum Pathol 1989;20:18-28.

5. Yardley JH, Lazenby AJ, Giardiello FM, Bayless TM. Collagenous, "microscopic", lymphocytic, and other gentler and more subtle forms of colitis. Hum Pathol 1990;21:1089-91.

6. Freeman HJ, Weinstein WM, Shnitka TK, Wensel R, Sartor V. Watery diarrhea syndrome associated with a lesion of the colonic basement membrane-lamina propria interface. Ann R Coll Phys Surg Can 1976;9:45.

7. Lindstrom CG. Collagenous colitis with watery diarrhea - a new entity. Pathol Eur 1976;11:87-9.

8. Freeman HJ. Collagenous inflammatory mucosal diseases of the gastrointestinal tract. Can J Gastroenterol 1990;4:196-200.

9. Wolber R, Owen D, Freeman H. Colonic lymphocytosis in patients with celiac sprue. Hum Pathol 1990;21:1092-6.

10. Hamilton I, Sanders S, Hopwood D, Bouchier IAD. Collagenous colitis associated with small intestinal villous atrophy. Gut 1986;27:1394-8

11. Breen EG, Coughlan G, Connolly CE, Stevens FM, McCarthy CF. Coeliac proctitis. Scand J Gastroenterol 1987;22:471-7.

12. Cadiot G, Flourie B, Galian A, Lavergne A, Modigliani R. Coeliac disease and collagenous colitis. A fortuitous association. Presse Med 1990;19:1621-2.

13. O'Mahony S, Nawroz IM, Ferguson A. Coeliac disease and collagenous colitis. Postgrad Med J 1990;66:238-41

14. Freeman HJ. Clinical spectrum of biopsy-defined celiac disease in the elderly. Can J Gastroenterol 1995;9:42-6.

15. Wolber R, Owen D, DelBuono L, Appelman H, Freeman HJ. Lymphocytic gastritis in patients with celiac sprue or sprue-like intestinal disease. Gastroenterology 1990;98:310-5.

16. Freeman HJ, Kwan WCP. Occult celiac disease associated with lymphocytic sclerosing cholangitis. Can J Gastroenterol 1994:8:249-52.

17. Armes J, Gee DC, Macrae FA, Schroeder W, Bhathal PS Collagenous colitis: jejunal and colorectal pathology. J Clin Pathol 1992;45:784-7.

18. Marks J, Shuster S, Watson AJ. Small bowel changes in dermatitis herpetiformis. Lancet 1966;ii:1280-2.

19. Weinstein WM. Latent celiac sprue. Gastroenterology 1974;66:489-93.
20. Freeman HJ, Piercey JRA, Raine RJ. Collagenous gastritis. Can J Gastroenterol 1989;3:171-4

21. Puri AS, Khan EM, Kumar M, Pandey R, Choudhuri G. Association of lymphocytic (microscopic) colitis with tropical sprue. J Gastroenterol Hepatol 1994;9:105-7.

22. Freeman HJ, Chiu BK. Multifocal small bowel lymphoma and latent celiac sprue. Gastroenterology 1986;90:1992-7.

23. Cooper BT, Holmes GKT, Ferguson R, Thompson RA, Allan RN, Cooke WT. Gluten-sensitive diarrhea without evidence of celiac disease. Gastroenterology 1980;79:801-6.

24. Ferguson A, Blackwell JN, Bartneson RStC. Effects of additional dietary gluten on the small intestinal mucosa of volunteers and of patients with dermatitis herpetiformis. Scand J Gastroenterol 1987;22:543-9.

25. Leonard J, Haffenden G, Tucker W. Gluten challenge in dermatitis herpetiformis. N Engl J Med 1983;308:816-9.

26. Fry L, McMinn RMH, Cowan JD, Hoffbrand AV. Gluten-free diet and reintroduction of gluten in dermatitis herpetiformis. Arch Dermatol 1969;100:129-35

27. Doherty M, Barry RE. Gluten-induced mucosal changes in subjects without overt small bowel disease. Lancet 1981;i:517-20.

28. Levine RA, Briggs GW, Harding RS, Nolte LB. Prolonged gluten administration in normal subjects. N Engl J Med 1966;274:1109-14.

29. Ferguson A, Murray D. Quantitation of intraepithelial lymphocytes in human jejunum. Gut 1971;12:988-94.

30. Savilahti E, Arato A, Verkasalo M. Intestinal gamma-delta receptor bearing $T$ lymphocytes in celiac disease and inflammatory diseases of children. Constant increase in celiac disease. Pediatr Res 1990;28:579-81

31. Maki M, Holm K, Collin P, Savilahti E. Increase in gamma-delta T cell receptor bearing lymphocytes in normal small bowel mucosa in latent coeliac disease. Gut 1991;32:1412-4.

32. Kutlu T, Brousse N, Rambaud C, Le Deist F, Schmitz J, Cerf-Bensussan N. Numbers of T cell receptor (TCR) alpha-beta positive but not of TcR gamma-delta positive intraepithelial lymphocytes correlate with the grade of villous atrophy in coeliac patients on a long term normal diet. Gut 1993;34:208-14.

33. Ferguson A, Arranz E, O'Mahony S. Clinical and pathological spectrum of coeliac disease - active, silent, latent, potential. Gut 1993;34:150-1. 


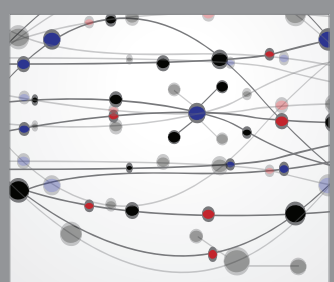

The Scientific World Journal
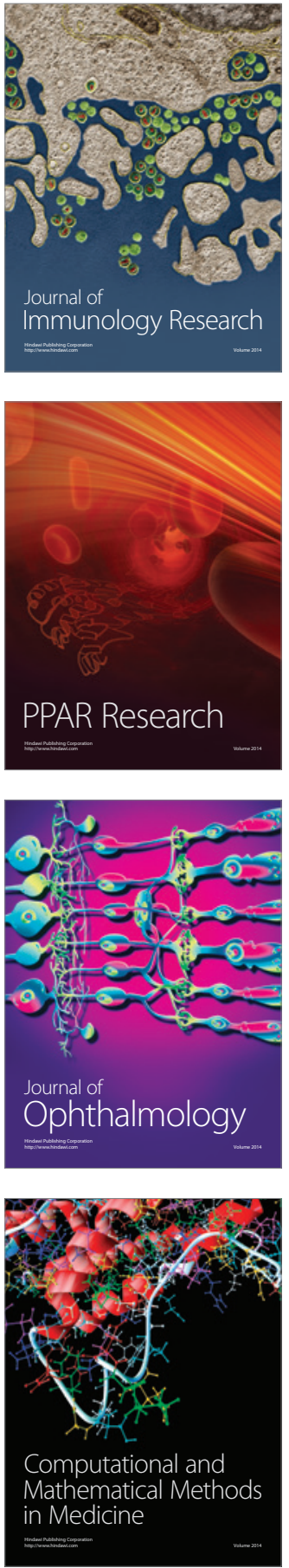

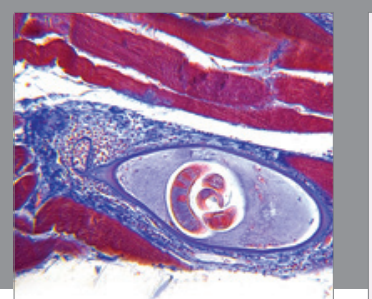

Gastroenterology Research and Practice

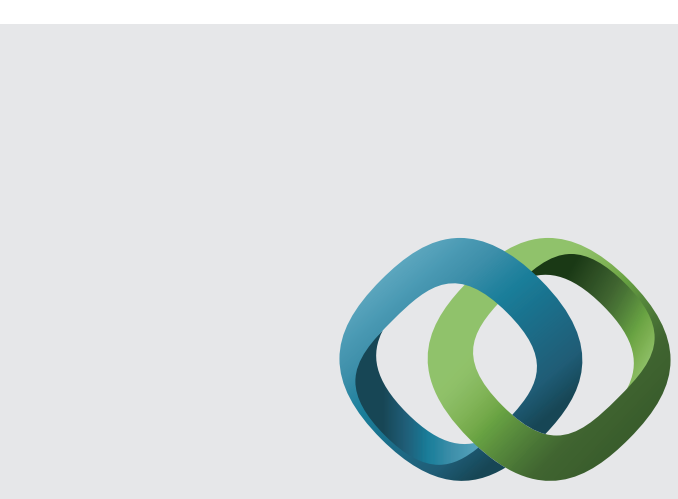

\section{Hindawi}

Submit your manuscripts at

http://www.hindawi.com
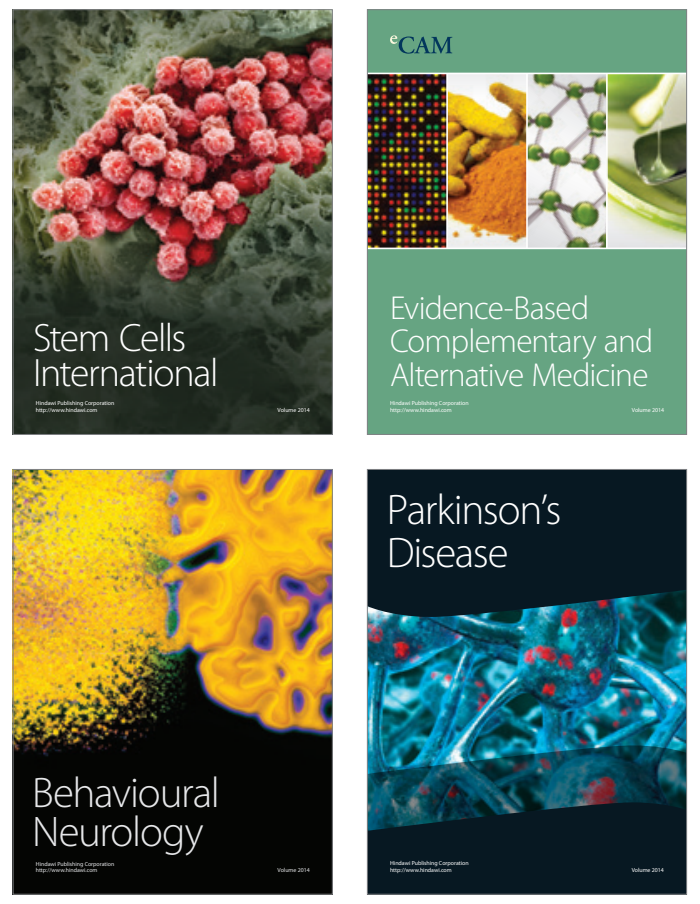
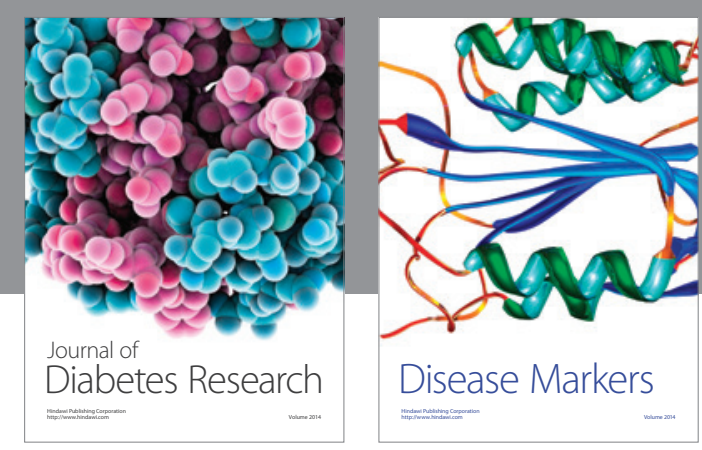

Disease Markers
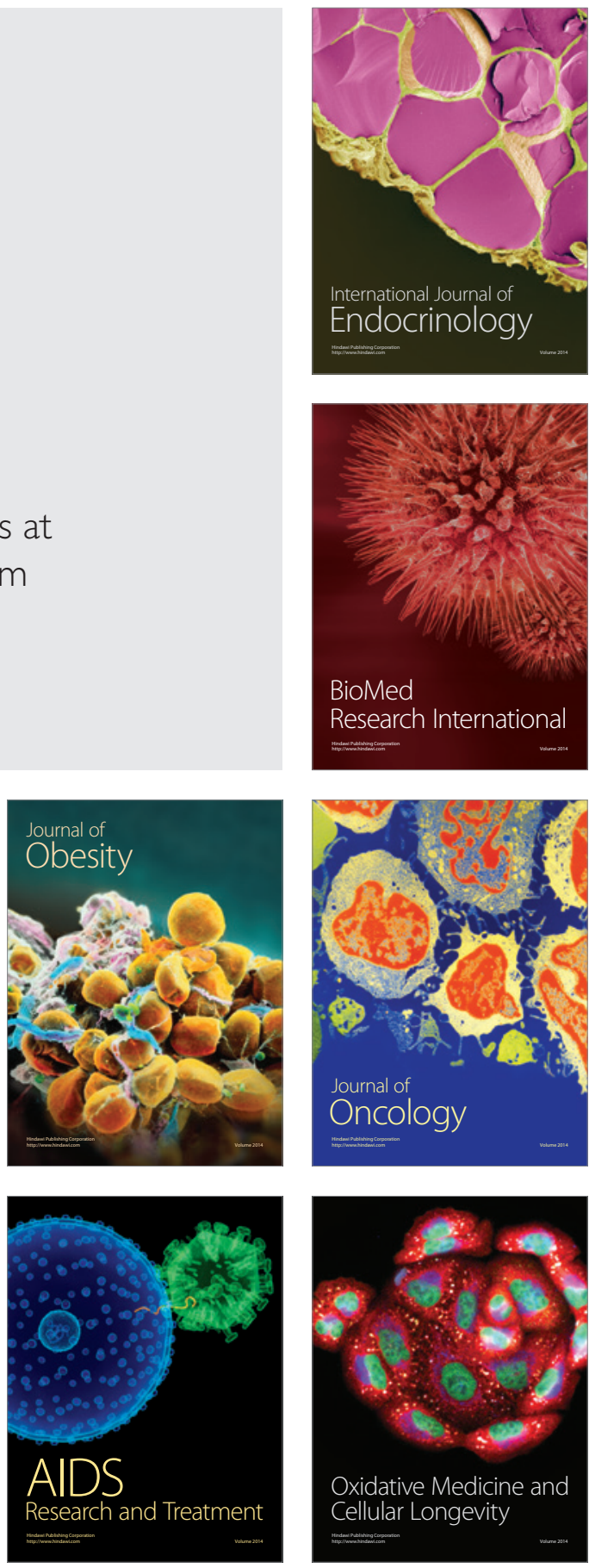